\section{Special effects: tobacco policies and low socioeconomic status girls and women}

\author{
Lorraine Greaves, Donna Vallone, Wayne Velicer
}

\section{Currently little is known about the specific effects of tobacco policies on low income girls and women. Research is vital on such effects both in developed and developing countries.}

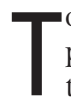
obacco use is a global public health problem of epic proportion, which threatens to kill one of two smokers and harm many non-smokers along the way. The World Health Organisation views both tobacco use and tobacco production as a dire threat to world health, contributing to early death, chronic diseases, poverty, environmental degradation, and labour exploitation. ${ }^{1}$ Tobacco use has typically been patterned along gender and class lines, with higher class males typically beginning to smoke before females and those in lower socioeconomic classes. ${ }^{2-4}$

In developed countries, there have been great successes in tobacco control, reducing rates of smoking by half in countries such as the USA, Canada, Sweden, Australia, and the United Kingdom over the past 40 years. These achievements reflect the success of the comprehensive tobacco policy approach, linking several key regulatory and legal policies together in the effort to reduce tobacco use. These policies include taxation, limits on advertising and sponsorship, restrictions on smoking locations, and prohibitions of sales to children. However, despite these successes, declining rates of tobacco use at the population level may mask high rates and persistent health issues for many disadvantaged groups, such as women and girls of low socioeconomic status (SES), within the same societies.

The combination of three issues, gender, class, and tobacco policy, coalesce to underpin this special supplement of the Journal of Epidemiology and Community Health. In particular, the authors of this issue, its funders, the National Cancer Institute and the American Legacy Foundation, and its sponsor, the Tobacco Research Network on Disparities (TReND), are concerned with the effects of comprehensive tobacco policies on low SES girls and women. There is little known about the specific effects of tobacco policies on low income girls and women. However, it is vital that we probe the effects of policies on various subpopulations around the world, both in developed and developing countries. As the authors in this special issue show, several factors underscore this concern.

Firstly, low SES people are especially susceptible to starting or continuing to smoke, even in developed countries when overall rates are rapidly declining. Levy et al point out that lower education and employment are linked with lower quit success, especially among women. ${ }^{5}$ Low SES women may bear a disproportionate health burden related to tobacco social and economic issues that contribute to inequity in health, as both Greaves and Jategaonkar and Graham et al point out. ${ }^{67}$ Several of the authors, including Shavers et al and Moore et al environment is potentially more difficult for low SES girls and women, as they may more often live in households with smokers or work at jobs where Moore et $\mathrm{al}^{9}$ and Greaves and Jategaonkar ${ }^{6}$ suggest, domestic power differentials between women and men may limit low SES women's ability to control their home environment.

All of these issues are of concern, but the overriding theme of this supplement is how do tobacco policies affect women and girls in these situations? Can their "biographies of disadvantage," as Graham et $\mathrm{al}^{7}$ label the pathways of many low SES girls and women toward smoking, be changed into biographies of advantage and trajectories free of smoking?

Several key research questions emerge. Firstly, are low SES girls and women affected differentially by tobacco policies, when compared with other groups? Secondly, how do these use, and experience a constellation of suggest that creating a smoke free smoking is permitted. ${ }^{8}$ Additionally, as broad policies interact with individual characteristics? Thirdly, are the effects positive or negative in terms of improving health? Fourthly, are these effects positive or negative in the context of improving social and economic health? Fifthly, how are low SES girls and women, both smokers and non-smokers, affected by tobacco policies? Sixthly, how do diverse low SES women, such as those in various ethnocultural and/or racialised groups, or those working or living in specific environments, experience tobacco policies? Seventhly, what new approaches could be developed to tailor tobacco policies for low SES girls and women that reflect the realities of their lives? And finally, how can we mitigate and reduce the unanticipated negative effects of tobacco policies on disparate groups, while increasing their positive effects?

These are complex questions, many of which are difficult to answer using existing data. Indeed, the authors of the special issue show that direct evidence pertaining to these questions is often lacking as these questions have rarely been asked in research. Both Kim et $a l^{10}$ and Shavers $e t a l^{8}$ show that new data are needed to better answer these questions. We also need to ask new questions of existing data. Levy et al show the value in re-analyses of large datasets. ${ }^{5}$ Both Moore et al ${ }^{9}$ and Balbach et $a l^{11}$ illustrate how qualitative methods or mixed qualitative and quantitative methods can be used to assess the full effects of tobacco policies on low SES girls and women. Finally, as Greaves and Jategaonkar ${ }^{6}$ and Graham et $a l^{7}$ suggest, new conceptual frameworks for designing ethical and truly comprehensive tobacco policies need to be used to assess and respond to the issues.

Given the large gaps in our knowledge, there is a lot that remains to be done to adequately address the issues raised here. However, the evidence presented here suggests that further research is needed, and the authors suggest some specific future directions to pursue. Levy et al declare that the relation between low SES and smoking is not immutable, and that media campaigns as well as tax and price increases will continue to assist in reducing smoking prevalence among low SES girls and women. ${ }^{5}$ Shavers et al conclude that home based smoke free policies show promise reducing smoking among low SES women, ${ }^{8}$ and Shopland et al suggest that smokefree homes are linked to higher rates of quitting. ${ }^{12} \mathrm{Kim}$ et al encourage future research and policy on individual level factors such as the availability of cigarettes to young girls at home as a predictive factor for initiation. ${ }^{10}$ 
Balbach et al offer a key lesson in learning from the tobacco industry and using affirming and authentic relationship building with women's groups, labour groups, and communities that experience high tobacco use or exposure. ${ }^{11}$ Moore et al suggest a focus on specific work environments, with a view to understanding power relations and ethnic and racial issues. ${ }^{9}$ Graham et al convincingly show that the issues linked to tobacco use among low SES women are wide ranging and serious. ${ }^{7}$ Poverty, housing, and welfare policies and general disadvantage lead to and link to tobacco use for many young low SES women. Finding solutions to limit the effects of this confluence of disadvantages is the real challenge. Finally, Greaves and Jategaonkar recommend that a concerted effort be put into developing an ethical and gendered framework for fully addressing the issues of tobacco use, tobacco policies, and low SES girls and women.

Environments make a difference with respect to initiation and cessation. Workplaces and homes can be sites of exposure to secondhand smoke, enable the acquisition of smoking, or be detrimental to quitting. Policies that are sensitive to power relations and economic dynamics may help low SES women reduce tobacco use and improve their health. The tobacco control movement has a part to play in working with low SES women, employee groups, unions, and communities to share expertise and resources in establishing and achieving mutual aims.

The larger environment matters as well. In response to the alarming spread of tobacco use across the world, particularly in countries previously minimally involved in tobacco production and use, the WHO spearheaded the first international public health treaty in the world, the Framework Convention on Tobacco Control (FCTC), ${ }^{13}$ which has, to date, acquired 168 signatories. The wide ranging provisions of the FCTC seek to control tobacco use and production across the world and to prevent a predicted devastating 21 st century epidemic, particularly among girls and women. ${ }^{14} 15$ The FCTC is especially concerned with the intersecting issues of gender, class, and poverty that affect the use of tobacco among girls and women. Alarm is expressed in the preamble about the rising spectre of tobacco use among some of the most vulnerable populations worldwide.

The authors in this issue suggest some specific approaches that can be taken, both in developed countries and developing countries, to address these issues. Firstly, no matter what stage of the tobacco use epidemic is being experienced, researchers, practitioners, and policy makers should be encouraged to apply a gender and diversity analysis in assessing the impact of tobacco policy. In addition, research into and suggestions for ameliorating any negative or unintended impacts should be as important as measuring successes.

Secondly, as both Greaves and Jategaonkar ${ }^{6}$ and Graham et al ${ }^{7}$ suggest, we need to recognise the constellation of disadvantage that confronts most low SES women smokers, and construction of policy in a broad, ethical, and involving manner. In this vein, linking housing, welfare, child care, training, and economic policies and programmes to tobacco policy is critical to achieve the desired effect on low SES girls and women's health.

Thirdly, we must determine how different levels of tobacco (and related) policies address the protection of low SES women's health. Which state, provincial, or national level policies will help? Which local or municipal policies will help? How do policies affect the micro-social worlds of low SES women in their relationships, families, friendship circles, or homes? What can be done to create protection and limit risk on behalf of low SES women, without presuming that their behaviour needs to change, independent of broader systemic changes?

Finally, the way the tobacco control movement has traditionally operated needs to change. The FCTC offers a commitment to highlighting issues of gender, poverty, and youth in particular, while expressing similar concern about indigenous populations and tobacco use. This international commitment is both an invitation and an opportunity for advancing the interests of low SES women in the effort to prevent and reduce tobacco use. To address these previously masked problems, we must consider meaningful partnerships with low SES girls and women, women's groups, community centres, ethnocultural groups, unions, programme providers, and women smokers as critical to making progress. The best ideas, the best evidence, and the best interventions will spring from developing authentic relationships and mutually supportive networks between tobacco control advocates and groups supporting low SES women. These approaches will move caring about low SES women smokers into the mainstream of tobacco control, a goal long overdue. Most important, it will offer low income women smokers some opportunities, and some hope.
$J$ Epidemiol Community Health 2006;60(Suppl II):ii1-ii2. doi: $10.1136 /$ jech.2006.052480

\section{Authors' affiliations}

L Greaves, British Columbia Centre of Excellence for Women's Health, Vancouver, Canada

D Vallone, American Legacy Foundation, Washington, USA

W Velicer, University of Rhode Island, USA

Correspondence to: $\operatorname{Dr} \mathrm{L}$ Greaves, BC Centre of Excellence for Women's Health, Box 48, E 311 4500 Oak Street, Vancouver, Canada, V6H 3N1; lgreaves@cw.bc.ca

Funding: the National Cancer Institute and the American Legacy Foundation.

Competing interests: none.

\section{REFERENCES}

1 Esson KM, Leeder SR. The millennium development goals and tobacco control: an opportunity for global partnership. Geneva: World Health Organisation, 2004.

2 Lopez AD, Collishaw NE, Piha T. A descriptive model of the tobacco epidemic in developed countries. Tob Control 1994;3:242-7.

3 World Bank. Curbing the epidemic: governments and the economics of tobacco control. Washington, DC: World Bank, 1999

4 Aghi M, Asma S, Yeong CC, et al. Initiation and maintenance of tobacco use. In: Samet JM, Yoon SY, eds. Women and the tobacco epidemicchallenges for the 21 st century. Geneva: World Health Organisation, 2001:49-68.

5 Levy DT, Mumford EA, Compton C. Tobacco control policies and smoking in a population of low education women, 1992-2002. J Epidemiol Community Health 2006;60(Suppl 2):ii20-6.

6 Greaves L, Jategaonkar N. Tobacco policies and vulnerable girls and women: toward a framework for gender sensitive policy development. J Epidemiol Community Health 2006;60(Suppl 2):ii57-65.

7 Graham H, Inskip HM, Francis B, et al. Pathways of disadvantage and smoking careers: evidence and policy implications. J Epidemiol Community Health 2006;60(Suppl 2):ii7-12.

8 Shavers VL, Fagan P, Jouridine LA, et al. Workplace and home smoking restrictions and racial/ethnic variation in the prevalence and intensity of current cigarette smoking among women by poverty status, TUS-CPS 1998-1999 and 2001-2002. J Epidemiol Community Health 2006:60(Suppl 2):ii34-43.

9 Moore RS, Lee JP, Antin TMJ, et al. Tobacco free workplace policies and low socioeconomic status female bartenders in San Francisco. J Epidemiol Community Health 2006;60(Suppl 2):ii51-6.

$10 \mathrm{Kim} \mathrm{H}$, Clark Pl. Cigarette smoking transition in women of low socioeconomic status: impact of state, school, and individual factors. J Epidemiol Community Health 2006;60(Suppl 2):ii 13-19.

11 Balbach ED, Herzberg A, Barbeau EM. Political coalitions and working women: how the tobacco industry built a relationship with the Coalition of Labor Union Women. J Epidemiol Community Health 2006:60(Suppl 2):ii27-32.

12 Shopland DR, Anderson CM, Burns DM. Association between home smoking restrictions and changes in smoking behaviour among employed women. J Epidemiol Community Health 2006;60(Suppl 2):ii44-50.

13 World Health Organisation. Framework convention on tobacco control. Geneva: World Health Organisation, 2003

14 Mackay J, Ericksen M. The tobacco atlas. Geneva: World Health Organisation, 2002.

15 Mackay J. Preface. In: Samet JM, Yoon SY, eds. Women and the tobacco epidemic-challenges for the 21 st century. Geneva: World Health Organisation, 2001. 